\title{
Game Interaction State Graphs for Evaluation of User Engagement in Explorative and Experience-based Training Games
}

\author{
Hiran Ekanayake ${ }^{1}$, Per Backlund ${ }^{1}$, Tom Ziemke ${ }^{1}$, Robert Ramberg ${ }^{2}$ and Kamalanath Hewagamage ${ }^{3}$ \\ ${ }^{1}$ University of Skövde, ${ }^{2}$ Stockholm University, ${ }^{3}$ University of Colombo School of Computing \\ \{hiran.ekanayake, per.backlund, tom.ziemke\}@his.se,robban@dsv.su.se,kph@ucsc.cmb.ac.lk
}

\begin{abstract}
Recent studies have shown that computer games can be used as an effective tool of instruction. There is an increasing interest to use computer games for non-traditional education, such as for training purposes. For training education, simulators are considered as offering more realistic learning environments to experience situations that are similar to real world. This type of learning is more beneficial for practicing critical situations which are difficult or impossible in real world training, for instance experience the consequences of unsafe driving. However, the effectiveness of simulation-based learning of this nature is dependent upon the learner's engagement and explorative behaviour. Most current learner evaluation systems are unable to capture this type of learning. Therefore, in this paper we introduce the concept of game interaction state graphs (GISGs) to capture the engagement in explorative and experience-based training tasks. These graphs are constructed based on rules which capture psychologically significant learner behaviours and situations. Simple variables reflecting game state and learner's controller actions provide the ingredients to the rules. This approach eliminates the complexity involved with other similar approaches, such as constructing a full-fledged cognitive model for the learner. GISGs, at minimum, can be used to evaluate the explorative behaviour, the training performance and personal preferences of a learner.
\end{abstract}

Keywords - serious games, game interaction, experience-based systems, engagement, driving simulator training

\section{INTRODUCTION}

The computer and video games industry is among the fastest growing industries in the world and in Sweden the sales has increased by 34\% totalling more than USD 375 millions in 2008 (Kovacevic, 2009). In U.S. the increase is $15 \%$ in 2008 totalling USD 11.7 billions (ESA, 2009). ESA (2009) also reports that in U.S. 68\% of households were playing computer and video games and the total number of game units sold was over 298 millions in the year 2008. This wide interest for computer and video games not only says that if it can be used as a medium of instruction it can serve as an effective tool of learning, but also it will serve as a profitable business. However, yet this effort has failed as there is lack of methods to analyse the effect of learning in learner players, especially in training games (Egenfeldt-Nielsen, 2006; Brennecke, 2009).

In our work we introduce the concept of game interaction state graphs (GISGs) to better evaluate the learner's engagement in explorative and experience-based training tasks in simulation-based games. These graphs are constructed based on parameters reflecting psychologically significant learner behaviours and situations which are important to their experience. For example, in a driving simulator learning game, the high speed driving is considered as more challenging than low speed driving. Thus, a good learning experience consists in both engaging in less challenging as well as challenging situations. This behaviour will improve the learner's longer-term fitness (Gros, 2010) and help the learner to identify personal limits, for example speed limits he can manage confidently.

Our method brings many advantages over other methods which either depends on complex cognitive models (Piselli et al., 2009) or hardware intensive psychometric methods (Song et al., 2006; Morris and Miller, 1996). More importantly, our method considers only the most important parameters that the player wants to control in the game world and parameters that come under the direct control of the player. For example, in a driving simulator training task the player tries to control the speed using the throttle action. This approach eliminates the need to consider the overall game complexity and the complexity of the player's thinking process.

This paper is organized as follows: In section II, we give a brief introduction to serious games; identify simulator-based gaming environments as an effective tool for training; how task performance depends upon one's emotional arousal and the importance of experience-based learning in driving education. In section III, we introduce the concept of GISGs, its design with respect to experience-based driver training and its usefulness. Finally, in section IV, we conclude by discussing the limitations of this approach and suggesting future work. 


\section{RELATED WORK}

\section{A. Serious Games and Simulation-based Training}

Most computer games available today focus on creating an entertaining experience to its end-users and this helps to interactively involve and motivate the players to continue playing (Mitchell and Savill-Smith, 2004). However, it is believed that games can be used to teach almost any subject or skill (Debul, 2006). With this objective, the serious games initiative has taken its path to contribute to and achieve some other defined purpose beyond pure entertainment in a more authentic way (Mitchell \& Smith, 2004; Brennecke, 2009; Backlund et al., 2010). Today serious games are used in a number of areas, e.g. education, skill training, health care and military.

Engagement is considered as an important parameter which makes a learning task more productive (Carini et al., 2006). With respect to serious games, the entertainment value serves as the primary factor which engages the users to the gaming task. Work related to evaluating the entertainment aspect of computer games suggest that it is related to both the subject's performance and the game complexity (Piselli et al., 2009). In game design, immersion, agency and transformation are considered as the three aesthetics which makes interactions in the digital medium particularly successful for users (Bayliss and Schwartz, 2009). Bayliss and Schwartz further suggest that immersion becomes the context enabling individuals to learn and agency encourages motivation. Backlund et al. (2007) suggest that simulation-based games in the sense of experience-based systems offer more learning performance for training tasks. Therefore, simulation-based games offer a higher degree of game complexity to more entertain and engage the users.

The user's performance in the gaming task is dependent upon the user's thinking process. A user may select to play the same game differently in different occasions to achieve different experiences. This subjective nature of user interactions makes the evaluation of user engagement in computer games more difficult. Studies related to measuring user engagement falls into several categories. In one such category researchers build cognitive models to model user's thought processes with similar activation rules and firing rates (Piselli et al., 2009). Another category of researchers study how psychometric measures, such as facial expressions and skin conductivity, can be used to recognize the user's level of engagement in the task (Song et al., 2006; Morris and Miller, 1996). However, these types of methods bring additional complexity to the game interaction.

\section{B. Mental Tasks and User Performance}

Due to limitations in cognitive and perceptual processing, humans are incapable of simultaneously processing all information received through the senses. To resolve this issue, the human brain functions in a certain way, called attention that filters out unimportant information and focuses only on a limited number of tasks and information required for those tasks (Galotti, 2004; Styles, 1997). The modal model of memory (Galotti, 2004) considers working memory as the memory area that contains information about the currently attended tasks. The attention coordinates information received from the outside environment and information retrieved from long term memories. Therefore, the attention provides the basis for engagement to tasks in humans.

Kahneman model of attention and mental effort explains the relationship between mental effort for tasks and attention with a more process oriented view (Galotti, 2004; Kahneman, 1973). According to his view, attention is a set of cognitive processes for categorizing and recognizing stimuli. The more complex the stimulus, the harder the processing, and therefore more resources are engaged. The availability of mental resources in the Kahneman model is affected by the overall level of emotional arousal. If the arousal is too high or too low, a smaller amount of capacity is available than if it is at the optimal level of arousal. On the other hand, the level of arousal also depends on the task's difficulty. This creates an "inverted-U" shaped relationship between level of arousal and performance in the mental task (Piselli et al., 2009).

\section{Driving Psychology and Road Safety}

Motor vehicle accidents are among the highest ranked cause of deaths worldwide. In U.S., over 37,000 deaths have been caused in 2008 as a result of motor vehicle accidents (NHTSA, 2008). According to Collet et al. (2005) greater percentage of vehicle crashes occur as the lack of capability of the driver to orient their attention in such situations, which is a result of bad vigilance, and this is directly determined by arousal.

Driving requires a focused attention to the task with an excessive amount of mental resources. The driving task, like any other mental tasks, follows the "inverted-U" shaped relationship between the arousal and task performance as depicted in Figure 1.

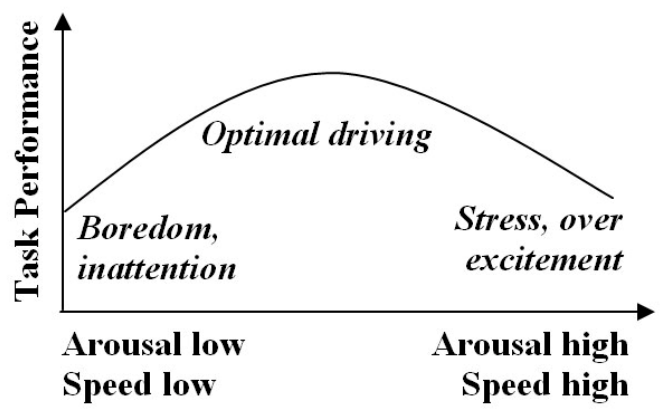

Figure 1 Arousal, Speed and Driving Performance (adapted from http://www.safespeed.org.uk/arousal.html) 
A driver at low speed driving on an empty motorway in otherwise good conditions will find it difficult to concentrate on the task while feeling more bored. At this level of arousal the performance of the driver is likely to be poor. As discussed by Lal and Craig (2001), driver fatigue (boredom) is a major cause of road accidents and it is responsible for up to $20-30 \%$ of road fatalities. On the other hand, a driver at very high speed driving will be under a great deal of stress as the person carries a mental overload due to large amount of information the person has to process. Under these mental conditions, it is more likely that the performance of the driver again becomes poor with respect to responding to critical conditions in the environment. Nevertheless, the driver may find it easy to concentrate and will feel comfortable when he drives at some moderate speed. Under moderate speed levels the performance of the driver becomes very high compared to the other two conditions. This fact is discussed in online blogs to suggest safe speed limits for road driving without sticking into traditional speed limits (see http://www.safespeed.org.uk/).

Another aspect of drivers' performance is their behaviour when they are confronted with a critical crash avoidance situation. A study conducted by Collet et al. (2005), in a private driving circuit, concludes that drivers who were avoiding the obstacles were more physiologically aroused than those who crashed into a dummy car.

These results point at the need for learners to have been confronted with and engaged in critical and psychologically significant conditions during their learning. Learners can be exposed to these and train these by using driving simulators. Ultimately, it will be a good experience for them when they involve with real driving.

\section{METHODOLOGY AND ANALYSIS}

\section{A. Driving Simulators and Driver Training}

Driving simulators bring many advantages to driving education, such as allowing learners to experience situations that are impossible in the real world for reasons of risk, cost, instructor time, and so forth. There is evidence that driving simulators with greater realism and technological complexity will allow people to seek to construct and learn from their virtual experiences in a similar manner to their everyday experiences (Backlund et al., 2008b).

As it has been discussed in the previous section, there are psychologically significant driving situations which are difficult or impossible to teach during real world driving lessons. However in driving simulators these types of situations can be repeated easily. One way to achieve this is by incorporating such situations into the lesson plan of the driving simulator training. We see a weakness of this approach, as if the learner's objective is only to learn how to drive and how to face these situations, then the learner naturally regulates his attention towards that task. However, after the completion of driver training, the person's primary task becomes something else while driving becomes a supportive task, for instance to drive to the office. In such situations, it is more likely that the person becomes less reactive to risky situations than in the simulator. Therefore, we encourage driver training tasks to be as true as possible to the real world so that the learner is allowed to experience many driving behaviours and critical situations, and their consequences in order to learn from experience.

One of the main problems of driver training of this nature will be to identify the learner's explorative behaviour and the learning effect quantitatively. For instance, a nervous learner will seek to drive in low speeds to avoid uncomfortable psychological hassle and a clever learner will avoid driving at high speeds to avoid crashes in a game-based simulator to safeguard his score. This second example also highlights the need for designing a scoring system for explorative and experience-based training systems as opposed to conventional scoring systems.

\section{B. Game Interaction State Graphs (GISGs)}

The previous section has identified requirement for a better evaluation method for explorative and experience-based training systems. In our work, we explore driver training using a game-based simulator. In a typical simulation-based training game the game creates a context, simulating a world model, in which the player has to practice task oriented activities. Different players may perceive this context differently, because of their differences in cognitive processes. Next, depending on the player's cognitive and emotional states, e.g. desire to win and avoid crashes, the player will tend to react through the available game controller. Once the game receives the player's reaction as a quantitative measure, the game advances its game logic by one step to change the game world accordingly. This new change once again triggers the player to react again and this process creates a continuous game play interaction.

In driver training, we identified the importance of the learner's engagement to different psychologically significant situations. One way to achieve this learning objective is by creating such scenarios into the game, for example while the player drives in a clear road, another vehicle can be made to suddenly cross into the player's driving path. However, design related discussions go beyond the scope of this paper. Our main goal of this paper is to present a method to capture the player's engagement in such situations. Although, the game is capable of rendering such situations, if the player does not perceive the scenario correctly, the expected learning effect would not occur. Therefore, it is essential to detect whether the player is engaged and orienting his actions correctly in such situations. We use this simple mechanism to determine the player's level of meaningful engagement. The following 
discussion is an example to demonstrate how a GISG can be constructed for a player who plays a driving simulator game.

Based on psychologically significant driver behaviours, such as low speed driving in which the driver may find it difficult to concentrate on the task, and situations, such as crashes which can be a result of bad vigilance, directly affecting traffic safety, the lesson plan of a driving simulator training game can be identified as Table 1 . The relative risk assessment in Table 1 reflects how a typical learner would perceive that behaviour/situation as challenging relative to another situation with respect to orienting his attention under the influence of arousal, which in this case as perceived by the authors.

TABLE 1 PSYCHOLOGICALly SignifiCANT DRIVER BEHAVIOURS/SITUATIONS AND THEIR RELATIVE RISK

\begin{tabular}{|l|l|c|}
\hline $\begin{array}{l}\text { Driving } \\
\text { behaviour/situation }\end{array}$ & $\begin{array}{l}\text { Psychological } \\
\text { significance }\end{array}$ & $\begin{array}{l}\text { Relative risk } \\
\text { factor }\end{array}$ \\
\hline Low speed driving & $\begin{array}{l}\text { Boredom and } \\
\text { inattention }\end{array}$ & 2 \\
\hline Moderate speed driving & Optimal attention & 1 \\
\hline High speed driving & $\begin{array}{l}\text { Over excitement, risk } \\
\text { taking and bad } \\
\text { judgment }\end{array}$ & 3 \\
\hline $\begin{array}{l}\text { Taking a turn in low } \\
\text { speed }\end{array}$ & Optimal attention & 2 \\
\hline $\begin{array}{l}\text { Taking a turn in } \\
\text { moderate speed }\end{array}$ & Risk taking & 3 \\
\hline $\begin{array}{l}\text { Taking a turn in high } \\
\text { speed }\end{array}$ & $\begin{array}{l}\text { Over excitement, risk } \\
\text { taking and bad } \\
\text { judgment }\end{array}$ & 4 \\
\hline Not line following & Risk taking & 2 \\
\hline Crash & $\begin{array}{l}\text { Result of bad } \\
\text { behaviour }\end{array}$ & 5 \\
\hline Not involved & No learning & 0 \\
\hline
\end{tabular}

In Table 1, each driving behaviour/situation is an interaction between the player and the game world. For example, the "low speed driving" is when the player put less pressure to the throttle and the car moves in low speed. This behaviour/situation can be determined if the speed of the car and the throttle pressure can be measured. However, not all behaviours/situations can be determined in this way, for instance, if the game does not give a measure about the track geometry, the behaviour/situation "taking a turn in low speed" can not be determined in a similar way. In such situations, the behaviour/situation can be approximated based on the player's action. For example, "taking a turn in low speed" can be approximately determined using throttle pressure and steering pressure. Once the parameters are identified, functions (rules) can be constructed to determine each behaviour/situation. For example, if throttle pressure is less than 0.5 and car velocity is less than $30 \mathrm{~km} / \mathrm{h}$, the resulting situation can be determined as "low speed driving". However, for a given set of parameter values, more than one behaviour/situation can arise as a result of functions that share similar parameters. To resolve such situations, we encourage another step involving conflict resolution using the relative risk assessment, i.e. the behaviour/situation with the highest relative risk value gets the most precedence. Figure 2 shows raw parameter values when a player is in engaged in a driving simulator game.

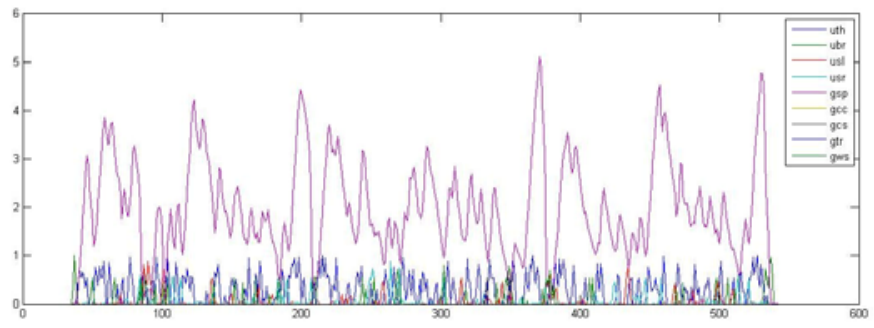

Figure 2 Raw parameter values, e.g. throttle pressure (uth), car speed (gsp), etc., captured when a player plays a driving simulator game.

As can be seen in Figure 2, it is difficult to analyse the gaming task only by looking at raw parameter values. Once the values are compiled against the behaviour/situation functions, the next level of abstraction, which we referred to as GISG, can be obtained as depicted in Figure 3. Note that to analyse the emotional reaction of a person, a time window of size between 1 to 10 seconds is required as suggested by Healey and Picard (1998).

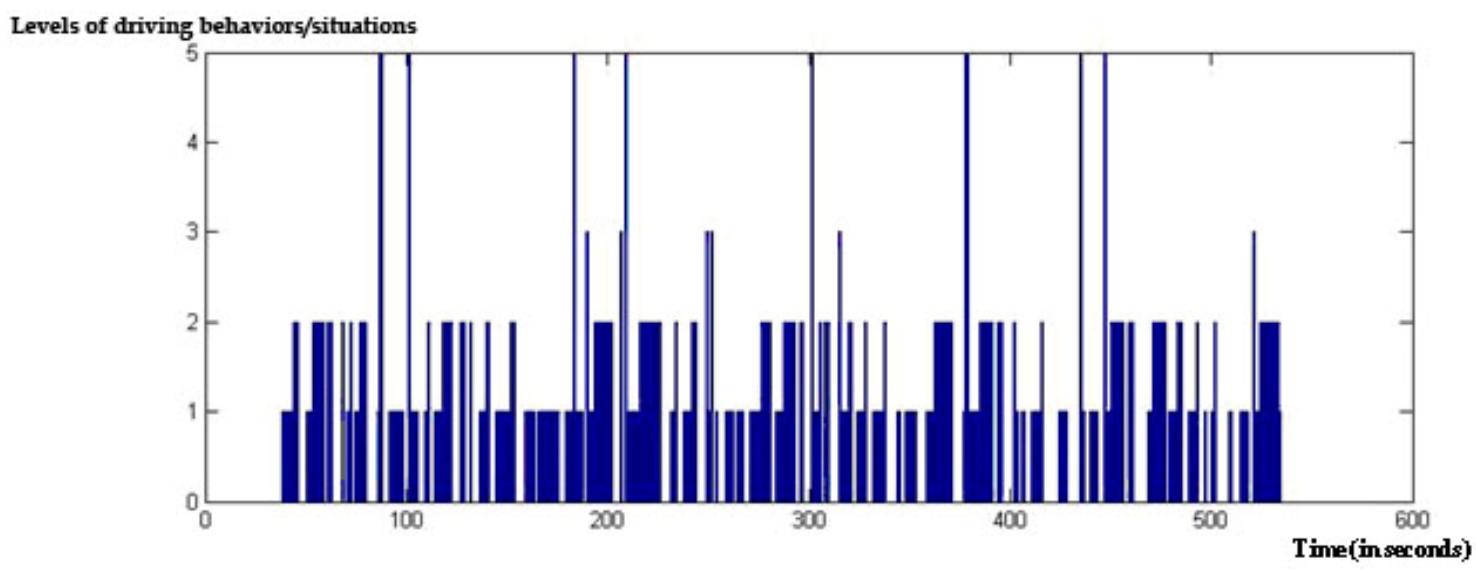

Figure 3 Game Interaction State Graph (GISG) for driver training 
The GISG, depicted in Figure 3, shows the learner's different driving behaviours and situations he has experienced and explored. According to Figure 3, this player has explored or experienced very low number of situations above level 2, i.e. behaviours/situations corresponding to "crashes", "taking a turn in high speed", etc. The player has preferred to stay between levels 1 and 2 .

\section{Usefulness of GISGs}

As discussed previously, a GISG represents a learner's engagement in different behaviours and situations he has experienced and explored during a training session. With respect to the driving example we have explored, at minimum, the GISG can be used to evaluate the player's explorative behaviour, the training behaviour and personal preferences.

The levels along the y-axis in a GISG represent different behaviours or situations with increasing risk assessment in the real world when the driver's psychology is concerned. For a complete training experience it is required that the player has reached and explored all these levels in a more distributed manner.

The training behaviour can be captured by analysing the GISG to see how the learner minimizes extreme risk situations, such as crashes in our example, while staying confidently at high risk situations, such as taking a turn in high speed. As it can be seen in Figure 3, this player has many state transitions from level 1or 2 to level 5, which corresponds to novice level of skills. It is expected that, an expert player will demonstrate smooth state transitions, with is supported by recent research showing that novice players are more sensitive to challenges in game play than experienced players (Gilleade et al., 2005).

In Figure 3, it can be observed that most of the time the learner has preferred to stay between the levels 1 and 2, which corresponds to low risk behaviours/situations. However, another player may prefer to stay within different levels. These parameters, i.e. mean, standard deviation and transitions, will capture personal preferences of the player.

\section{IV.DISCUSSION AND FUTURE WORK}

This paper has introduced the concept of game interaction state graphs (GISGs) for the evaluation of a player's engagement in different behaviours and situations in a gamebased training task. A GISG adds an abstract view to game interaction variables, which are otherwise very difficult to analyse and understand. For example, how the speed of a car affects the psychological performance of a driver. There are many other benefits of GISGs, such as to evaluate the explorative behaviour, training behaviour and personal preferences.
We used a driver training example to demonstrate the concept. In Table 1, we presented some identified driver behaviours/situations which we perceived as psychologically significant situations. However, to strive for a full fledged training system more in line with what is discussed in this paper, it is required that a thorough study is conducted to identify the situations and parameters to capture the situations. Also, there can be personal differences on how one person defines one situation over another person. For example, one may define "low speed driving" as car speed less than 30 $\mathrm{km} / \mathrm{h}$ while another person may feel it less than $15 \mathrm{~km} / \mathrm{h}$.

The engagement measurement is the primary concern in our work. To measure this we capture the player's action through the game controller. These action parameters with parameters from the game determine the psychological meaning of that interaction. However, for an accurate evaluation of the player's psychological engagement, it is required that psychometric parameters of the player are also captured. For instance, the player may still put throttle pressure, but the player may be in a psychologically frustrated state.

As the next step in our study, we have planned an experiment to validate and evaluate our concept for achieving the mentioned benefits. The study continues integrating electroencephalography (EEG) based psychometric measurements to capture the player's psychological engagement to improve the accuracy of the method.

\section{ACKNOWLEDGMENT}

The authors wish to sincerely thank the InGaMe lab at University of Skövde. This work has been financed through the NeLC project of SPIDER program.

\section{REFERENCES}

[1] Kovacevic, A. (2009). Computer game nation. The official gateway to Sweden.

[http://www.sweden.se/eng/Home/Business/Reading/Computer-gamenation/] (March 3, 2010).

[2] ESA (2009). Essential Facts about the Computer and Video Game Industry. Entertainment Software Association, Fact sheet. [http://www.theesa.com/facts/pdfs/ESA_EF_2009.pdf] (March 3, 2010).

[3] Egenfeldt-Nielsen, S. (2006). Overview of Research on the Educational Use of Video Games. Digital Kompetanse. 1 (3), 184-213.

[4] Brennecke, A. (2009). A General Framework for Digital Game-Based Training Systems. Doctoral thesis, University of Rostock.

[5] Gros, C. (2010). Cognition and Emotion: Perspectives of a Closing Gap. Cognitive Computation 2(2):78-85.

[6] Piselli, P., Claypool, M., and Doyle, J. (2009). Relating Cognitive Models of Computer Games to User Evaluations of Entertainment. 
Proceedings of the 4th International Conference on Foundations of Digital Games, April 26-30, 2009, Orlando, Florida.

[7] Song, K.S., Park, J.H., and Jeong, S.M. (2006), Enhancing eLearning Interactivity via Emotion Recognition through Facial Expressions. In Proceedings of ICL 2006.

[8] Morris, T.L. and Miller, J.C. (1996). Electrooculographic and performance indices of fatigue during simulated flight. Biological Psychology 1996; 42(3): 343-60.

[9] Mitchell, A. and Savill-Smith, C. (2004). The use of computer and video games for learning. London: Learning and Skills Development Agency.

[10] Debul, P. (2006). Game on!: Game-based learning. T.H.E. Journal, 33(6), 30-33, 41. Available: http://www.thejournal.com/articles/17788 (accessed 11 May 2009).

[11] Backlund, P., Engström, H., Johannesson, M and Lebram, M. (2010) Games for traffic education: An experimental study in a game-based driving simulator. Simulation \& Gaming vol. (41) issue (2). DOI: $10.1177 / 1046878107311455$.

[12] Carini, R.M., Kuh, G.D., and Klein, S.P. (2006). Student Engagement and Student Learning: Testing the Linkages. Research in Higher Education, 47 (1), 1-32.

[13] Bayliss, J.D. and Schwartz, D.I. (2009). Instructional Design as Game Design. ICFDG 2009, April 26-30, 2009, Orlando, FL, USA.

[14] Backlund, P., Engstrom, H., Hammar, C., Johannesson, M., and Lebram, M. (2007). Sidh - a Game Based Firefighter Training Simulation. 11th International Conference Information Visualization (IV '07), pp.899-907, 2007.
[15] Galotti, K.M. (2004). Cognitive Psychology: In and Out of the Laboratory, 3rd Edition, Indian Reprint 2007.

[16] Styles, E.A. (1997). The psychology of attention, Hove, UK: Psychology Press.

[17] Kahneman, D. (1973). Attention and Effort. Englewood Cliffs, NJ: Prentice-Hall.

[18] NHTSA (2008). National Highway Traffic Safety Administration. Fatal Crashes 1994 - 2008 - State : USA. [http://wwwfars.nhtsa.dot.gov/Trends/TrendsGeneral.aspx] (June 05, 2010).

[19] Collet, C., Petit, C., Priez, A., and Dittmar, A. (2005). Stroop colorword test, arousal, electrodermal activity and performance in a critica driving situation. Biological Psychology, 69, 195-203.

[20] Lal, S.K.L. and Craig, A. (2001). A critical review of the psychophysiology of driver fatigue, Biological Psychology 55 (2001), pp. 173-194.

[21] Backlund, P., Engström, H., Johannesson, M., Lebram, M., and Sjödén, B. (2008b) Designing for self-efficacy in a game based simulator: An experimental study and its implications for serious games design. In Bannatyne, M. et al. (Eds.) Proceedings of Vis'2008, London, UK, July 9-11, pp. 106-113, IEEE Computer Society, ISBN: 978-0-76953271-4.

[22] Healey, J., and Picard, R. (1998). Digital Processing of Affective Signals. In Proceedings of the ICASSP '98.

[23] Gilleade, K.M., Dix, A. and Allanson, J. (2005). Affective Videogames and Modes of Affective Gaming: Assist Me, Challenge Me, Emote Me. In Proceedings of DiGRA 2005. Vancouver, BC, Canada. 